\title{
Uncoupling Protein 2 Deficiency Enhances NLRP3 Inflammasome Activation Following Hyperglycemia-Induced Exacerbation of Cerebral Ischemia and Reperfusion Damage In Vitro and In Vivo
}

\author{
Ting Zhang ${ }^{1} \cdot$ Mao-Tao He ${ }^{1,2}\left(\right.$ D $\cdot$ Xiao-Peng Zhang ${ }^{1} \cdot$ Li Jing $^{1} \cdot$ Jian-Zhong Zhang ${ }^{1}$ \\ Received: 23 November 2020 / Revised: 4 February 2021 / Accepted: 5 February 2021 / Published online: 18 March 2021 \\ (c) The Author(s) 2021
}

\begin{abstract}
Mitochondrial uncoupling protein 2 (UCP2) deficiency exacerbates brain damage following cerebral ischemia/reperfusion (I/R). The Nod-like receptor protein-3 (NLRP3) inflammasome also plays a vital role in cerebral I/R damage. However, the effect of UCP2 on NLRP3 inflammasome-mediated hyperglycemia and I/R damage is not clear. In the present study, $\mathrm{UCP} 2$-knockout $\left(\mathrm{UCP}^{--}{ }^{-}\right.$) and wild-type (WT) mice were used to establish a model of middle cerebral artery occlusion (MCAO) and reperfusion under normo- and hyperglycemic conditions. HT22 cells were established as a model of oxygen-glucose deprivation and reoxygenation (OGD/R) with high glucose to mimic hyperglycemia and I/R in vitro. HT22 cells were treated with/without different concentrations of the UCP2-specific inhibitor genipin for different periods of time. The results showed that UCP2 deficiency significantly increased histopathological changes and apoptosis after cerebral I/R damage in hyperglycemic mice. Moreover, UCP2 deficiency enhanced NLRP3 inflammasome activation in neurons when cerebral I/R damage was exacerbated by hyperglycemia. Furthermore, UCP2 deficiency enhanced NLRP3 inflammasome activation and reactive oxygen species (ROS) production in HT22 cells under OGD/R and high-glucose conditions. UCP2 deficiency aggravated hyperglycemia-induced exacerbation of cerebral I/R damage. UCP2 deficiency also enhanced NLRP3 inflammasome activation and ROS production in neurons in vitro and in vivo. These findings suggest that UCP2 deficiency enhances NLRP3 inflammasome activation following hyperglycemia-induced exacerbation of cerebral I/R damage in vitro and in vivo. UCP2 may be a potential therapeutic target for hyperglycemia-induced exacerbation of cerebral I/R damage.
\end{abstract}

Keywords Uncoupling protein $2 \cdot$ Cerebral ischemia $\cdot$ Hyperglycemia $\cdot$ Reactive oxygen species $\cdot$ Nod-like receptor protein-3

\section{Abbreviations \\ UCP2 Uncoupling protein 2 \\ $\mathrm{UCP} 2^{-/-} \quad \mathrm{UCP} 2$ deficiency \\ $\mathrm{I} / \mathrm{R} \quad$ Ischemia/reperfusion \\ MCAO Middle cerebral artery occlusion}

Ting Zhang, Mao-Tao He and Xiao-Peng Zhang have contributed equally to this work.

Li Jing

1203220205@qq.com

Jian-Zhong Zhang

zhangjz@nxmu.edu.cn

1 School of Basic Medical Sciences, Ningxia Key Laboratory of Vascular Injury and Repair, Ningxia Medical University, Yinchuan 750004, Ningxia, China

2 Department of Pathology, General Hospital of Ningxia Medical University, Yinchuan 750004, Ningxia, China

$\begin{array}{ll}\text { WT } & \text { Wildtype } \\ \text { NG } & \text { Normoglycemic } \\ \text { HG } & \text { Hyperglycemic } \\ \text { TUNEL } & \begin{array}{l}\text { Terminal deoxynucleotidyl transferase medi- } \\ \text { ated dUTP nick-end labeling }\end{array} \\ & \text { Reactive oxygen species } \\ \text { STZ } & \text { Streptozotocin } \\ \text { OGD/R } & \text { Oxygen-glucose deprivation/reoxygenation } \\ \text { GE } & \text { Genipin } \\ \text { CCA } & \text { Common carotid artery } \\ \text { DHE } & \text { Dihydroethidium } \\ \text { NLRP3 } & \text { NLR family, pyrin domain containing } 3 \\ \text { ASC } & \text { Apoptosis associated speck-like protein } \\ \text { TXNIP } & \text { Thioredoxin-interacting protein }\end{array}$




\section{Introduction}

Ischemic stroke is identified as one of the major causes of disability and mortality worldwide. Hyperglycemia is an important independent risk factor for ischemic stroke and induces the occurrence and development of cerebral I/R damage $[1,2]$. Previous studies have shown that the exacerbation of ROS production, promotion of neuroinflammation, and extensive programmed cell death are possible mechanisms associated with hyperglycemia-exacerbated cerebral I/R damage. Recent evidence suggests that inflammation is a major factor in cerebral I/R damage due to the inflammatory response and the accumulation of inflammatory cells [3, 4]. However, the molecular mechanism by which hyperglycemia exacerbates ischemic brain injury is still unclear. To date, no effective drugs have been found to treat hyperglycemia-exacerbated ischemic brain injury. Thus, research on neuroprotection and targeted inflammation is very important in preventing and treating hyperglycemia-exacerbated cerebral I/R damage.

UCP2 is the inner membrane protein of mitochondria. It has been proposed that $\mathrm{UCP} 2$ regulates the mitochondrial potential and reactive oxygen species (ROS) production [5]. To date, several studies have found that UCP2 plays vital roles in cerebral I/R damage. UCP2 deficiency may enhance brain I/R damage by upregulating the protein levels of inflammatory cytokines and inhibiting antioxidants [6]. The neuroprotective effects of UCP2 are likely related to the regulation of ROS and neuroinflammation. However, the effect of UCP2 on the NLRP3 inflammasome in hyperglycemic and ischemic damage is not clear.

The inflammasome plays an important role in neuroinflammation. The NLRP3 inflammasome is a multiprotein complex that comprises NLRP3, ASC and caspase 1. NLRP3 inflammasome activation leads to NLRP3 recruitment of ASC and pro-caspase 1, which causes caspase-1 activation and the release of caspase activation-dependent cytokines, including IL-1 $\beta$ and IL-18. NLRP3 inflammasome activation may trigger or exacerbate neuroinflammation, thereby promoting cerebral ischemia injury $[7,8]$.

In this study, we hypothesized that UCP2 deficiency enhances NLRP3 inflammasome activation after hyperglycemia-exacerbated cerebral I/R damage. Thus, we used UCP2-knockout (UCP2 $2^{--}$) and wild-type (WT) mice to establish a model of middle cerebral artery occlusion (MCAO) and reperfusion under normo- and hyperglycemic conditions in vivo. HT22 cells were established as a model of oxygen-glucose deprivation and reoxygenation (OGD/R) with high glucose to mimic hyperglycemia and $\mathrm{I} / \mathrm{R}$ in vitro. HT22 cells were treated with/without different concentrations of the UCP2-specific inhibitor genipin for different times. We evaluated the effects of UCP2 deficiency and the activation of the NLRP3 inflammasome in hyperglycemia-induced exacerbation of cerebral ischemic injury.

\section{Materials and Methods}

\section{Materials}

A TUNEL assay kit (\#11684817910) was purchased from Roche (Mannheim, Germany). Streptozotocin (STZ) was purchased from Sigma. An ROS assay kit (\#S0033) was obtained from Beyotime (Shanghai, China). NLRP3 (ab214185), NeuN (ab104224) and IL-1 $\beta$ (ab9722) antibodies were purchased from Abcam (Cambridge, UK). ASC (D2W8U) and TXNIP (D5F3E) antibodies were obtained from Cell Signaling Technology (MA, USA). Caspase 1 (AF5418) and cleaved caspase-1 (AF4005) antibodies were purchased from Affinity. $\beta$-Actin and GAPDH antibodies were purchased from Bioss (Beijing, China). Genipin (Sigma-Aldrich, MO, USA) was diluted to appropriate concentrations in cell culture medium. ELISA kits were purchased from Abcam.

\section{Animals and Groups}

Breeding pairs of $\mathrm{UCP} 2^{-/-}$mice on a $\mathrm{C} 57 \mathrm{BL} / 6$ background were originally obtained from the Jackson Laboratory (USA). $\mathrm{UCP} 2^{-l-}$ mice were fed and bred in sterile animal housing, and age-matched male mice were used for the experiments. Male wild-type (WT) C57BL/6 mice (6-8 weeks old) were obtained from Vital River Laboratory (Beijing, China). All experimental protocols and procedures were approved by the Institutional Animal Care and Use Committee of Ningxia Medical University and the ethical review committee of Ningxia Medical University (approval document no. 2017-040). Animal experimental procedures were performed according to the NIH Guide for Care and Use of Laboratory Animals.

In the present study, a total of 54 male WT mice and $58 \mathrm{UCP}^{-/-}$mice were used. $\mathrm{UCP} 2^{-/-}$and WT mice were randomly divided into the sham (sham-operated) group, $\mathrm{NG}+\mathrm{I} / \mathrm{R}$ (normoglycemic $+1 \mathrm{~h} \mathrm{MCAO}$ and $24 \mathrm{~h}$ reperfusion) group, and $\mathrm{HG}+\mathrm{I} / \mathrm{R}$ (hyperglycemic $+1 \mathrm{~h}$ MCAO and $24 \mathrm{~h}$ reperfusion) group. Hyperglycemia was induced in male mice by streptozotocin (STZ) $(120 \mathrm{mg} / \mathrm{kg}$, body weight, i.p.). The blood glucose level was measured with a blood glucose meter $72 \mathrm{~h}$ after STZ injection. According to our previous experience, hyperglycemia was designated as a fasting blood glucose level of more than $16.8 \mathrm{mmol} / \mathrm{L}$ [9]. 


\section{Middle Cerebral Artery Occlusion Model}

Mice were anesthetized with 2-3\% isoflurane during induction, and anesthesia was maintained with $1.5-1.8 \%$ isoflurane during the operation. The right middle cerebral artery occlusion (MCAO) model was established using the filament method. Briefly, the right common carotid artery (CCA), internal carotid artery (ICA), and external carotid artery (ECA) were first separated. Second, a small incision was made in the CCA, and a filament (Doccol Corporation, USA) was inserted into the ICA to block the MCA. Finally, after $1 \mathrm{~h}$ of occlusion, animals were anesthetized again, the filament was removed, and reperfusion was performed for $24 \mathrm{~h}$. The mice in the sham group were subjected to the same surgical procedures without blocking the MCA. During the surgery period, the body temperature of the animal was monitored and maintained at $37 \pm 0.5^{\circ} \mathrm{C}$ with an animal body temperature maintenance instrument (RWD Life Science, Shenzhen, China). The average body temperature of animal during the operation was quantified. After operation, the animal was put into animal intensive care units (Lyon Technologies, Los Angeles, USA) for recovery. The neurological deficit was scored by Zea-Longa's scale [10]: (0) no neurological deficits; (1) failure to fully extend left paw; (2) circling to the left; (3) falling to the left; (4) unable to walk spontaneously and exhibiting depressed levels of consciousness. The mice were subjected to a neurological examination immediately after the animals recovered from anesthesia to judge the successful induction of MCAO model. The animal with scores of two and above was selected as the successful MCAO model [11]. Four animals with Zea-Longa's score less than two were excluded from the study. The animals were subjected to a neurological examination again after $24 \mathrm{~h}$ reperfusion to compare the neurological deficit between the experiential groups. All animals were coded with a number and the people who further process the measurements and analysis were blinded to the experimental conditions.

\section{Hematoxylin-Eosin (HE) Staining}

First, the mouse brains were made into paraffin blocks of brain tissue. Then, the brain tissue block was sliced into $4 \mu \mathrm{m}$ sections using a microtome. The sections were deparaffinized and rehydrated in a gradient of xylene and ethanol (xylene I for $10 \mathrm{~min}$, xylene II for $10 \mathrm{~min}, 100 \%$ ethanol I for $10 \mathrm{~min}, 100 \%$ ethanol II for $10 \mathrm{~min}, 90 \%$ ethanol for $5 \mathrm{~min}, 80 \%$ ethanol for $5 \mathrm{~min}, 70 \%$ ethanol for $5 \mathrm{~min}, 60 \%$ ethanol for $5 \mathrm{~min}, 50 \%$ ethanol for $5 \mathrm{~min}$, and $\mathrm{ddH}_{2} \mathrm{O}$ for $5 \mathrm{~min}$ ). Then, the sections were stained with hematoxylin for $4 \mathrm{~min}$. Next, the sections were stained with eosin for $1 \mathrm{~min}$. Finally, the sections were dehydrated and gently covered with coverslip slides. Images were acquired under a highpower field $(400 \mathrm{X})$ with a microscope, and the percentage of karyopyknotic cells was calculated. The cortical area in five brain slices per mouse was quantified.

\section{TdT-Mediated dUTP Nick-end Terminal dUTP Nick-End Labeling (TUNEL) Assay}

For the detection of apoptosis, brain sections were stained with a TUNEL kit (Roche, \#11684795910) according to the manufacturer's protocols. Briefly, the sections were deparaffinized and rehydrated in a gradient of ethanol. Then, proteinase $\mathrm{K}$ working solution was used to digest the tissues for $30 \mathrm{~min}$ at $37^{\circ} \mathrm{C}$. After rinsing, the TUNEL reaction mixture was added to the sections for $45 \mathrm{~min}$ at $37^{\circ} \mathrm{C}$. Finally, DAPI was applied to the sections, and the sections were covered with a coverslip. TUNEL-positive cells were observed with a fluorescence microscope, and the percentage of TUNELpositive cells was calculated.

\section{Cell Culture and Groups}

The mouse hippocampal neuronal cell line HT22 was originally obtained from ATCC (Rockville, MD, USA). HT22 cells were maintained in Dulbecco's modified Eagle's medium (DMEM) (HyClone laboratories, Waltham, MA) supplemented with $1 \%$ penicillin/streptomycin (HyClone) and $10 \%$ fetal bovine serum (FBS, HyClone). The cells were cultured in an incubator at $37{ }^{\circ} \mathrm{C}$ with $90 \%$ relative humidity and $5 \% \mathrm{CO}_{2}$. The cell medium was replaced per $24 \mathrm{~h}$.

The high glucose, genipin and OGD/R groups were as follows: NG group (control treatment of HT22 cells); HG group (high glucose treatment of HT22 cells); NG+OGD/R group (OGD/R treatment of HT22 cells); $\mathrm{HG}+\mathrm{OGD} / \mathrm{R}$ group (OGD/R and high glucose treatment of HT22 cells); $\mathrm{NG}+\mathrm{OGD} / \mathrm{R}+\mathrm{GE}$ group $(\mathrm{OGD} / \mathrm{R}$ and genipin treatment of HT22 cells); and $\mathrm{HG}+\mathrm{OGD} / \mathrm{R}+\mathrm{GE}$ group (OGD/R, high glucose, and genipin treatment of HT22 cells). According to previous studies, the selected high glucose concentration was $50 \mathrm{mM}$. Glucose was dissolved in PBS to prepare a stock solution and added to the medium at a final concentration of $50 \mathrm{mM}$. The concentration of glucose in the DMEM that was used was $25 \mathrm{mM}$. Cells cultured in culture medium containing $25 \mathrm{mM}$ glucose were used as normoglycemic controls.

\section{Oxygen-Glucose Deprivation/Reoxygenation Model and Drug Treatment}

First, the cell culture medium was changed to glucose-free medium, and then the cells were placed in a hypoxic incubator (MIC-101, Billups-Rothenberg Inc) containing 95\% $\mathrm{N}_{2}$ and $5 \% \mathrm{CO}_{2}$ at $37^{\circ} \mathrm{C}$ for $1 \mathrm{~h}$. Finally, the glucose-free medium was replaced with normal medium and reoxygenated for $24 \mathrm{~h}$. 
For genipin treatment, HT22 cells were plated on 96-well plates (5000 cells/well) $24 \mathrm{~h}$ before the treatments. After adherence, the cells were treated for $24 \mathrm{~h}$ with different concentrations of genipin $(25,50,75$, and $100 \mu \mathrm{M})$. At the end of the incubation, cell viability was determined via cell counting kit-8 (CCK-8) (Rockville, MD).

\section{Cell Viability Assay}

In brief, HT22 cells were plated at 5000 cells/well in 96-well plates. The cells were exposed to different treatments after $24 \mathrm{~h}$ of adhesion. After an additional $24 \mathrm{~h}$ of incubation, the absorbance was recorded by a SpectraMax reader. The relative intensity of the control group was designated as $100 \%$ cell viability, and the corresponding percentages of the experimental groups were calculated relative to the control group.

\section{ROS Production Assay}

HT22 cells were incubated in culture medium containing $20 \mu \mathrm{mol} / \mathrm{L}$ dihydroethidine (DHE) for $30 \mathrm{~min}$ in the different groups, washed twice with PBS, and fixed in 4\% paraformaldehyde in PBS for $15 \mathrm{~min}$. Intracellular ROS production was assessed with a fluorescence microscope. Images were captured at $400 \mathrm{X}$ magnification, and the intensity was evaluated by IPP6.0 image analysis software.

\section{Western Blot}

Mouse brain tissues or HT22 cells were lysed in RIPA lysis buffer containing protease inhibitor cocktails. The protein concentration was measured using a BCA assay kit. Equal amounts of protein $(50 \mu \mathrm{g} /$ well $)$ were loaded into wells for $10 \%$ SDS-PAGE, and the resultant gel was transferred to polyvinylidene fluoride membranes. The membrane was incubated with primary antibodies in blocking buffer at $4{ }^{\circ} \mathrm{C}$ overnight. The following primary antibodies were used: NLRP3 (1:300), ASC (1:1000), caspase 1 (1:1000), cleavedcaspase 1 (1:1000), UCP2 (1:500), superoxide dismutase (SOD2) (1:1000), TXNIP (1:1500), IL-1 $\beta$ (1:2000), and pro-IL-1 $\beta$ (1:1000). GAPDH $(1: 1000)$ and $\beta$-actin (1:5000) were used as internal controls for protein loading. Then, the membrane was incubated with secondary antibodies at room temperature for $1 \mathrm{~h}$. Imaging was performed using a BIORAD imaging system, and the ratio of the target protein level to GAPDH or $\beta$-actin was calculated.

\section{Immunofluorescence}

The paraffin-embedded brain sections were boiled for antigen retrieval in citrate buffer. Then, the sections were blocked for 20 min with $10 \%$ goat serum at room temperature. Next, the sections were incubated with primary antibodies at $4{ }^{\circ} \mathrm{C}$ overnight. After being washed three times with PBS, the sections were incubated with secondary antibodies at $37^{\circ} \mathrm{C}$ for $1 \mathrm{~h}$, and DAPI was added for $5 \mathrm{~min}$ in the dark.

HT22 cells from the different groups were seeded on glass slides. The slides of cells were fixed with $4 \%$ paraformaldehyde and permeabilized with $0.2 \%$ Triton X-100. The following steps were the same as those described above.

\section{ELISA}

The levels of IL- $1 \beta$ and IL-18 in the cell culture supernatant and serum were measured by mouse IL-1 $\beta$ and IL-18 ELISA kits (Abcam, USA) according to the manufacturer's instructions.

\section{Statistical Analysis}

Each experiment was independently repeated a minimum of three times. Statistical analysis was performed with IBM SPSS Statistics version 20.0. All values are expressed as the mean \pm standard deviation (SD) or as a percentage of the control. The datasets were analyzed by ANOVA followed by the LSD post-hoc test. Statistical significance was set at $p<0.05$.

\section{Results}

\section{UCP2 Deficiency Exacerbated Cerebral I/R-Induced Histopathological Changes and Apoptosis in Hyperglycemic Mice}

To determine whether UCP2 deficiency exacerbates cerebral I/R damage in hyperglycemic mice, infarct volume was evaluated by TTC staining. Figure $1 \mathrm{a}$ and $\mathrm{b}$ show that the infarct volume was increased in hyperglycemic mice compared with normoglycemic mice. UCP2 deficiency significantly increased the infarct volume compared with that of WT mice. Neurological deficit scores were significantly increased in hyperglycemic mice compared with normoglycemic mice. As expected, blood glucose levels were significantly higher in hyperglycemia mice than in normoglycemic mice. However, there was no difference in blood glucose levels between WT and UCP2 ${ }^{-/-}$animals (Table 1). During the surgery period, the body temperature of the animal was maintained at $37 \pm 0.5{ }^{\circ} \mathrm{C}$ with an animal body temperature maintenance instrument and recorded the average body temperature during the operation for quantification. The average body temperature during the operation was not statistically different between $\mathrm{UCP}^{-/-}$and WT animals under the same glycemic conditions (Table 1). The histopathological outcomes in the cortical area are shown in Fig. 1f. In the sham 
Fig. 1 UCP2 deficiency exacerbated I/R-induced histopathological changes and apoptosis in hyperglycemic mice. a Representative images of TTC staining in each group. b Bar graph summarizing the percent infarction volume in WT and $\mathrm{UCP} 2^{-/-}$mice. c Assessment of neurological deficits. d HE staining and TUNEL staining. e Quantitative summary of pyknotic cells. f Bar graph summarizing the percentage of TUNEL-positive cells. ${ }^{\#} p<0.05$ vs. the WT group; * $p<0.05$ vs. the NG group $(n=6$ in each group)
A

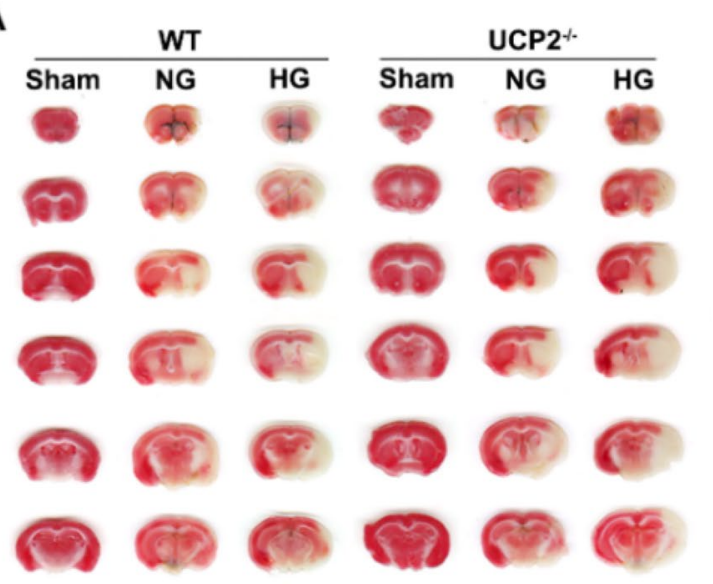

B
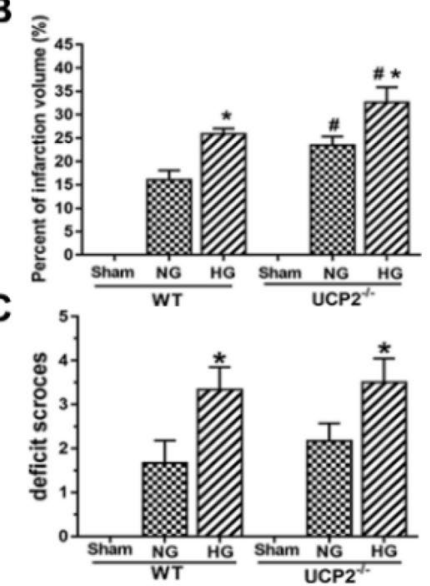

D

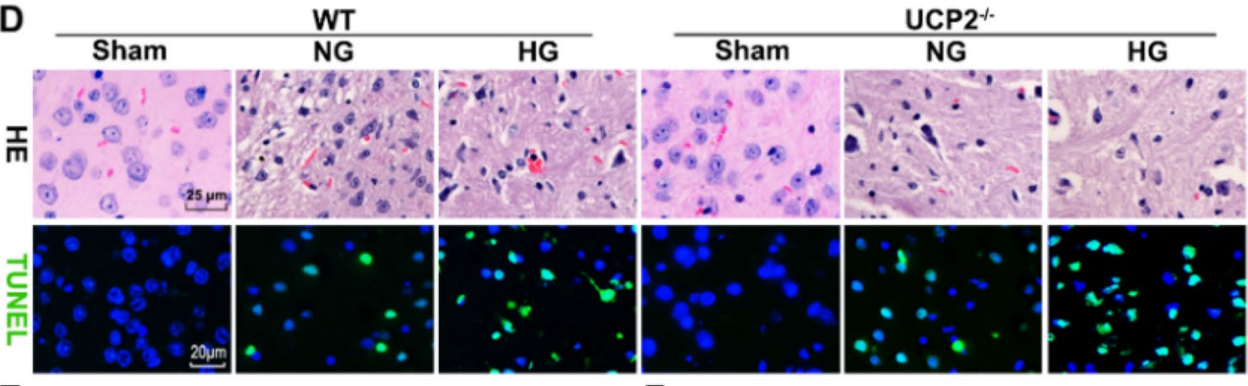

E
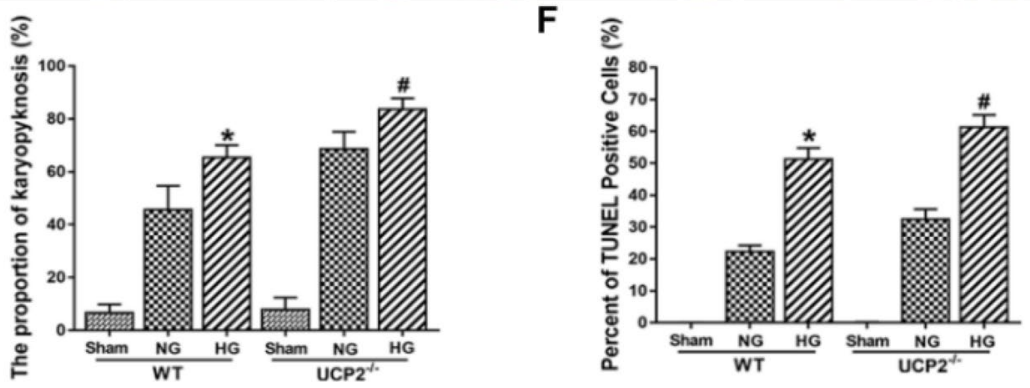

Table 1 Blood glucose and body temperature among different groups

\begin{tabular}{|c|c|c|c|c|c|c|}
\hline \multirow[t]{2}{*}{ Group } & \multicolumn{3}{|l|}{ WT } & \multicolumn{3}{|l|}{$\mathrm{UCP} 2^{-I-}$} \\
\hline & Sham & NG & HG & Sham & NG & HG \\
\hline Blood glucose $(\mathrm{mmol} / \mathrm{L})$ & $6.89 \pm 1.24$ & $6.32 \pm 1.46$ & $25.73 \pm 3.39 *$ & $6.53 \pm 1.39$ & $7.15 \pm 1.86$ & $24.77 \pm 5.68 *$ \\
\hline Body temperature $\left({ }^{\circ} \mathrm{C}\right)$ & $36.79 \pm 0.32$ & $36.85 \pm 0.20$ & $36.74 \pm 0.34$ & $36.81 \pm 0.37$ & $36.77 \pm 0.24$ & $36.76 \pm 0.31$ \\
\hline
\end{tabular}

${ }^{*} p<0.05$ vs. the NG group ( $\mathrm{n}=6$ in each group). Body temperature: The average body temperature during the operation

group, only a few dead cells were observed. The number of dead neurons in the cortical area was slightly increased in WT mice after I/R. UCP2 deficiency further increased the number of dead neurons after cerebral $\mathrm{I} / \mathrm{R}$ in normoglycemic and hyperglycemic mice. Furthermore, the TUNEL assay revealed that the number of TUNEL-positive cells obviously increased after cerebral I/R damage. Similarly, UCP2 deficiency further increased TUNEL-positive cells after cerebral I/R damage in normoglycemic and hyperglycemic mice (Fig. 1f). These results demonstrated that UCP2 deficiency enhanced histopathological changes and apoptosis after cerebral I/R damage in hyperglycemic mice.

\section{UCP2 Deficiency Enhanced NLRP3 Inflammasome Activation after Cerebral I/R Damage in Hyperglycemic Mice}

To determine whether UCP2 deficiency enhances NLRP3 inflammasome activation after cerebral I/R damage, the expression of NLRP3 inflammasome-related proteins was 
measured by western blotting, and the release of IL-1 $\beta$ and IL-18 was determined by ELISA. The results showed that NLRP3, cleaved caspase 1, and caspase 1 increased after cerebral I/R damage. UCP2 deficiency further increased the expression of NLRP3, cleaved caspase 1 , and caspase 1 after cerebral I/R damage in normoglycemic and hyperglycemic mice. Similarly, UCP2 deficiency increased the expression of ASC, TXNIP, and IL- $1 \beta$ after cerebral I/R damage in hyperglycemic mice. The inflammatory cytokines IL- $1 \beta$ and IL-18 were upregulated by UCP2 deficiency after cerebral I/R in hyperglycemic mice (Fig. 2h, i). These results indicated that UCP2 deficiency enhanced NLRP3 inflammasome activation in mice with cerebral I/R damage and hyperglycemia.

\section{UCP2 Deficiency Promotes NLRP3 Inflammasome Activation in Neurons Under Hyperglycemia-Exacerbated Cerebral I/R Conditions}

To further confirm that UCP2 deficiency promotes NLRP3 inflammasome activation in the cortical penumbra area, we used double immunostaining of NLRP3 and cleaved caspase 1 with NeuN (a neuronal marker) in $\mathrm{UCP} 2^{-/-}$mouse brain sections after I/R damage. Double labeling of NLRP3 and cleaved caspase 1 with the neuronal marker NeuN (Fig. 3a and $b$ ) in brain sections revealed that NLRP3 and cleaved caspase 1 colocalized with NeuN-positive neurons, suggesting that NLRP3 inflammasome activation occurred in neurons after cerebral I/R damage. Immunofluorescence analysis showed that the percentages of NLRP3- and cleaved caspase-1-positive neurons increased after cerebral I/R damage in normoglycemic and hyperglycemic mice. UCP2 deficiency further increased the expression of NLRP3 and cleaved caspase 1 in neurons in the context of hyperglycemia-exacerbated cerebral I/R damage. These results demonstrated that NLRP3 inflammasome activation occurred in neurons in UCP2 $2^{-/-}$mice with hyperglycemia-exacerbated cerebral I/R damage. Therefore, this study focused on the effect of UCP2 deficiency on the expression of NLRP3 inflammasome components in neurons in the context of hyperglycemia-exacerbated cerebral I/R damage.

\section{UCP2 Deficiency Enhanced HT22 Cell Damage Under Oxygen-Glucose Deprivation and Reoxygenation and High Glucose Conditions}

Because the NLRP3 inflammasome is expressed in neurons, we used hippocampal HT22 neurons to explore whether UCP2 deficiency affects the NLRP3 inflammasome activation pathway. Genipin is a specific UCP2 inhibitor that was
A

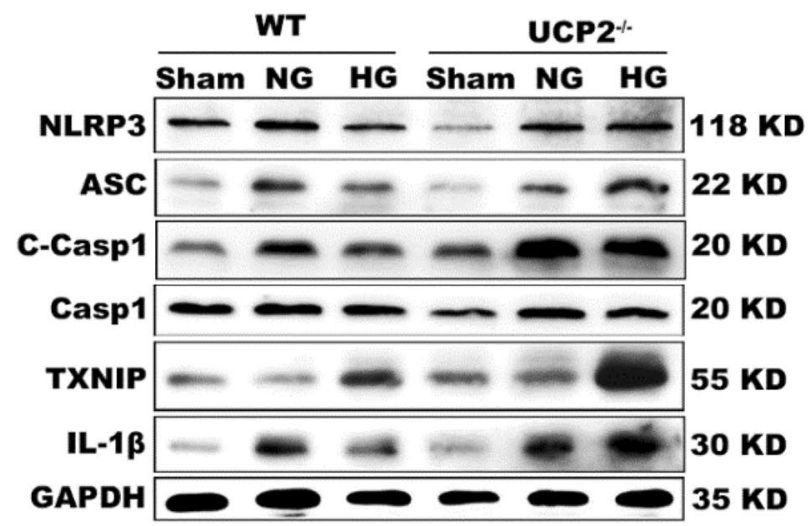

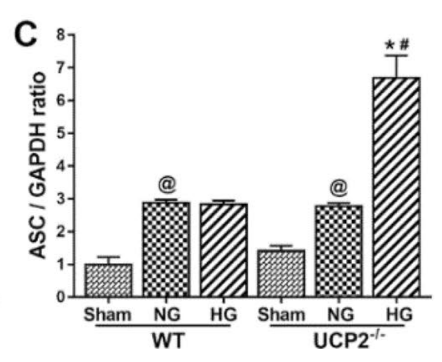

Fig. 2 UCP2 deficiency enhanced NLRP3 inflammasome activation after cerebral I/R damage in hyperglycemic mice. a The expression of NLRP3, cleaved caspase 1, caspase 1, ASC, TXNIP, and IL-1 $\beta$ in the different groups of UCP2-/- and WT mice. $\mathbf{b}-\mathbf{g}$ Semiquantitative
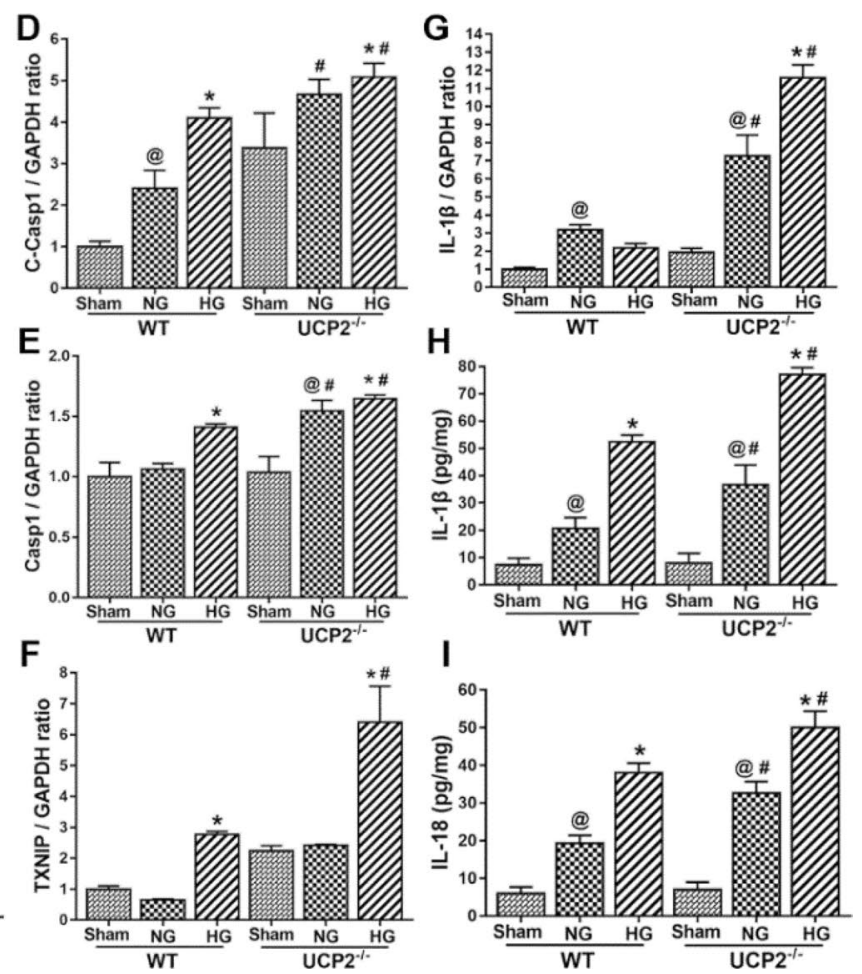

analysis of NLRP3, cleaved caspase 1, caspase 1, ASC, TXNIP, and IL-1 $\beta$ protein expression. $\mathbf{h}, \mathbf{i}$ The level of IL-1 $\beta$ and IL-18 in serum. ${ }^{\circledR} p<0.05$ vs. the sham group; ${ }^{*} p<0.05$ vs. the WT group; ${ }^{*} p<0.05$ vs. the NG group ( $n=6$ in each group) 

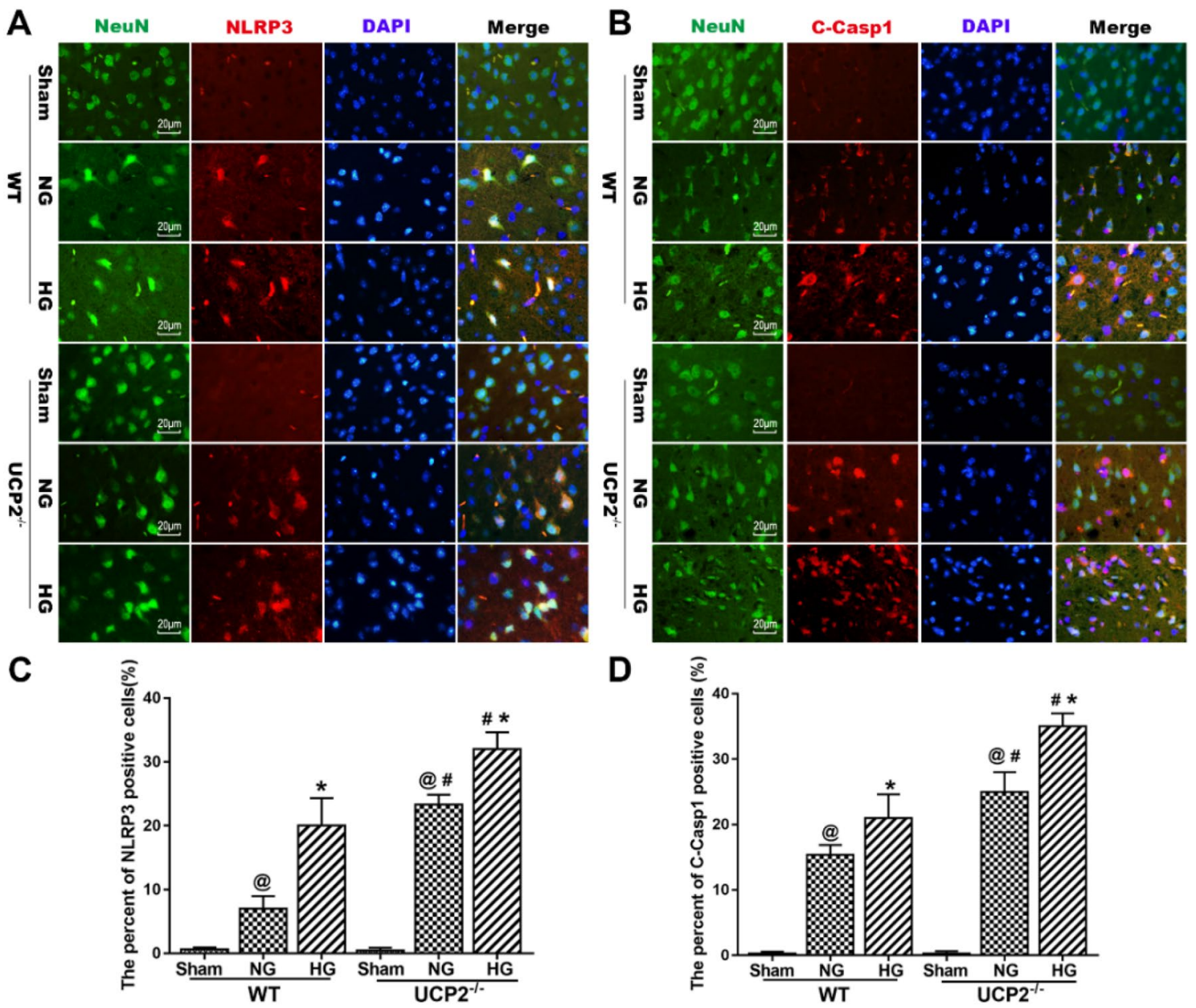

Fig. 3 UCP2 deficiency promotes NLRP3 inflammasome activation in neurons under hyperglycemia-exacerbated cerebral $I / R$ conditions. a Representative images showing double immunofluorescence staining for NLRP3 (red) and NeuN (green) in the cortical penumbra area. b Representative images of double immunofluorescence staining for cleaved caspase 1 (red) and NeuN (green) in the cortical

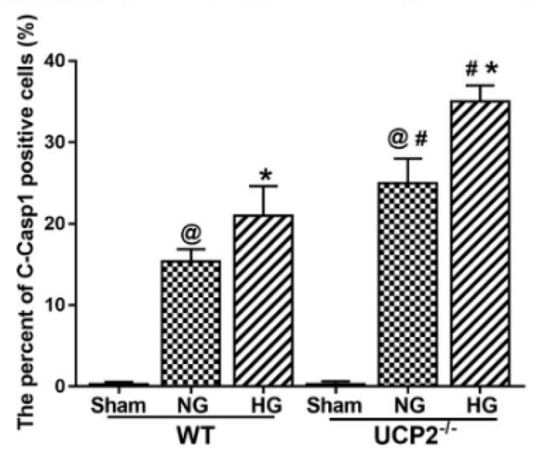

penumbra area. $\mathbf{c}$ The percentage of NLRP3-positive cells in the cortical penumbra area. d The percentage of cleaved caspase 1-positive cells (\%) in the cortical penumbra area. ${ }^{\circledR} p<0.05$ vs. the sham group; ${ }^{\#} p<0.05$ vs. the WT group; ${ }^{*} p<0.05$ vs. the NG group $(\mathrm{n}=6$ in each group)

To further assess the influence of UCP2 deficiency on used to explore the role of UCP2 in HT22 cells. To determine the effect of genipin on the expression of UCP2 and cell viability, we treated HT22 neuronal cells with genipin. First, a dose-response experiment was performed on HT22 cells treated with genipin for 24 and $48 \mathrm{~h}$. Figure $4 \mathrm{a}$, b shows that cell viability was not changed in response to genipin $(25-100 \mu \mathrm{M})(p>0.05)$. Then, the expression of UCP 2 was measured by western blotting after genipin treatment. Figure $4 c, d$ shows that the protein expression of UCP2 significantly decreased after $25 \mu \mathrm{M}$ genipin treatment for $24 \mathrm{~h}$. Increasing the drug concentration and treatment time did not affect the expression of UCP2. Therefore, we chose $25 \mu \mathrm{M}$ genipin treatment for $24 \mathrm{~h}$ for subsequent experiments. HT22 cells exposed to OGD/R and high glucose conditions, we assessed cell viability with a CCK- 8 kit. Figure $4 \mathrm{e}$ shows representative images of HT22 cell morphology under a light microscope. OGD/R resulted in cell shrinkage and nuclear condensation, suggesting cell damage. After the addition of genipin to inhibit UCP2 expression, cell damage worsened. The CCK-8 results (Fig. 4f) showed that NG + OGD/R decreased cell viability to $78 \%$ and that $\mathrm{OGD} / \mathrm{R}+\mathrm{HG}$ further decreased cell viability to $71 \%$. After the addition of genipin to inhibit UCP2 expression, $\mathrm{NG}+\mathrm{OGD} / \mathrm{R}$ reduced cell viability to $68 \%$, and $\mathrm{HG}+\mathrm{OGD} / \mathrm{R}$ further reduced cell viability to $58 \%$. These results indicated that UCP2 deficiency enhanced HT22 cell damage under OGD/R and high glucose conditions. 
A

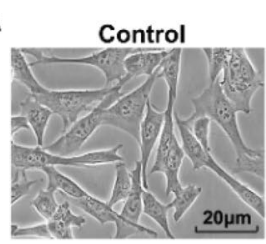

GE $75 \mu \mathrm{M}$

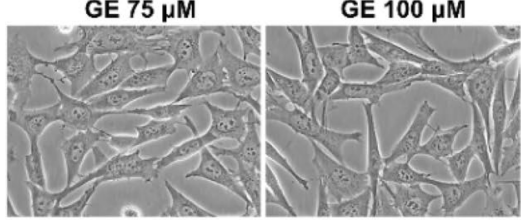

C

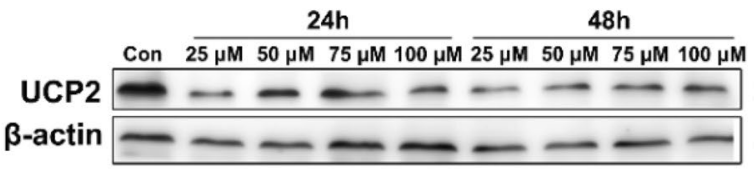

$33 \mathrm{KD}$

$\beta$-actin

E

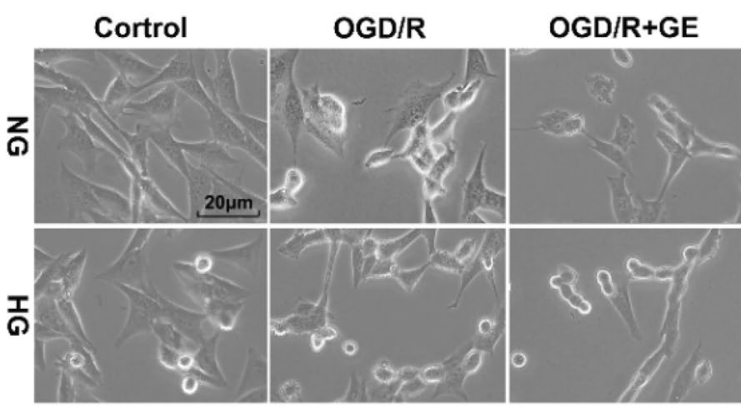

B
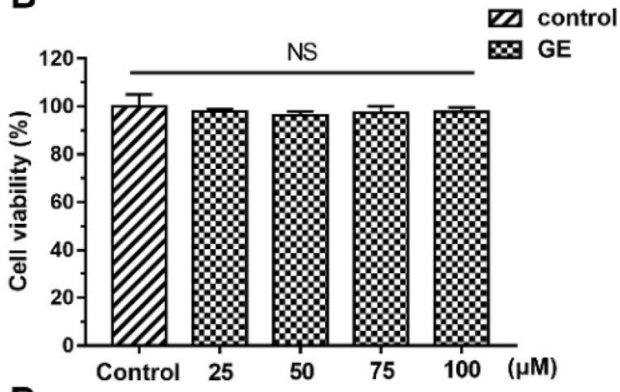

D

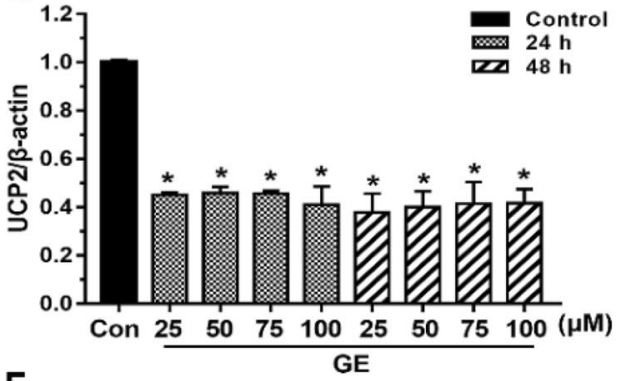

$\mathbf{F}$

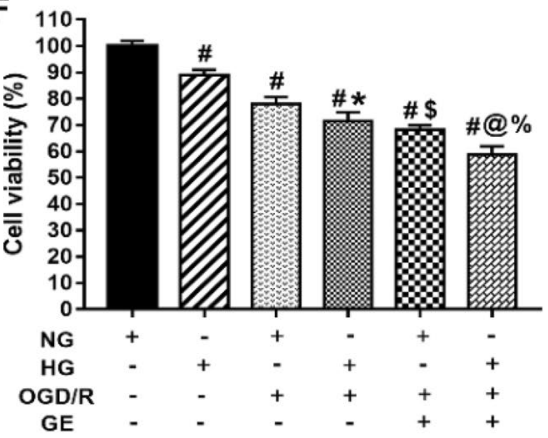

Fig. 4 UCP2 deficiency enhanced HT22 cell damage under OGD/R and high glucose conditions. a Light microscopy images showing morphological changes in HT22 cells treated with different concentrations of genipin $(25 \mu \mathrm{M}, 50 \mu \mathrm{M}, 75 \mu \mathrm{M}$, and $100 \mu \mathrm{M})$. b Cell viability in HT22 cells at different concentrations was determined by CCK- 8 assays. $\mathbf{c}, \mathbf{d}$ The expression of UCP2 in the different groups at the indicated times was measured by western blotting.

\section{UCP2 Deficiency Enhanced NLRP3 Inflammasome Activation in HT22 Cells Under OGD/R and High Glucose Conditions}

To investigate the role of UCP2 deficiency on NLRP3 inflammasome activation in HT22 cells under OGD/R and high glucose conditions, we measured the expression of NLRP3 inflammasome proteins, including NLRP3, ASC, cleaved caspase 1 , caspase 1 , TXNIP, and IL-1 $\beta$, using western blotting and immunofluorescence. Western blotting showed that OGD/R increased the protein levels of NLRP3, ASC, cleaved caspase 1, caspase 1, TXNIP, and IL-1 $\beta$. Concurrent treatment with genipin further increased the expression of NLRP3, ASC, cleaved caspase 1, caspase 1, TXNIP, and IL- $1 \beta$ in HT2 2 cells under normal and high glucose
${ }^{*} p<0.05$ vs. the Control group. e Light microscopic images showing morphological changes in HT22 cells after different treatments. Scale bar $=20 \mu \mathrm{m}$. f Cell viability analysis of HT22 cells after different treatments. The experiments were repeated three times in triplicate for each condition. ${ }^{\#} p<0.05$ vs. Control; ${ }^{*} p<0.05$ vs. HG; ${ }^{\$} p<0.05$ vs. NG+OGD/R; ${ }^{\circledR} p<0.05$ vs. $\mathrm{HG}+\mathrm{OGD} / \mathrm{R} ;{ }^{\%} p<0.05$ vs. $\mathrm{NG}+\mathrm{OGD} / \mathrm{R}+\mathrm{GE}$

conditions. These results suggest that OGD/R activates the NLRP3 inflammasome in HT22 cells. After genipin was added to inhibit UCP2 expression, the NLRP3 inflammasome was further activated. Immunofluorescence analysis confirmed the changes in NLRP3, ASC, cleaved caspase 1 , caspase 1 and IL-1 $\beta$ (Fig. 5a). The results showed that almost no neurons were positive for NLRP3, ASC, caspase 1 , cleaved caspase 1 or IL-1 $\beta$ in the normal control cells. OGD/R increased the immunoreactivity of NLRP3, ASC, cleaved caspase 1 , caspase 1 and IL-1 $\beta$ in the cytoplasm under normal and high glucose conditions. Genipin treatment significantly increased the number of NLRP3-, ASC-, caspase 1-, cleaved caspase 1-, and IL-1 $\beta$-positive cells in the $\mathrm{NG}+\mathrm{OGD} / \mathrm{R}$ and $\mathrm{HG}+\mathrm{OGD} / \mathrm{R}$ groups. Similarly, the ELISA results showed that OGD/R caused significant 

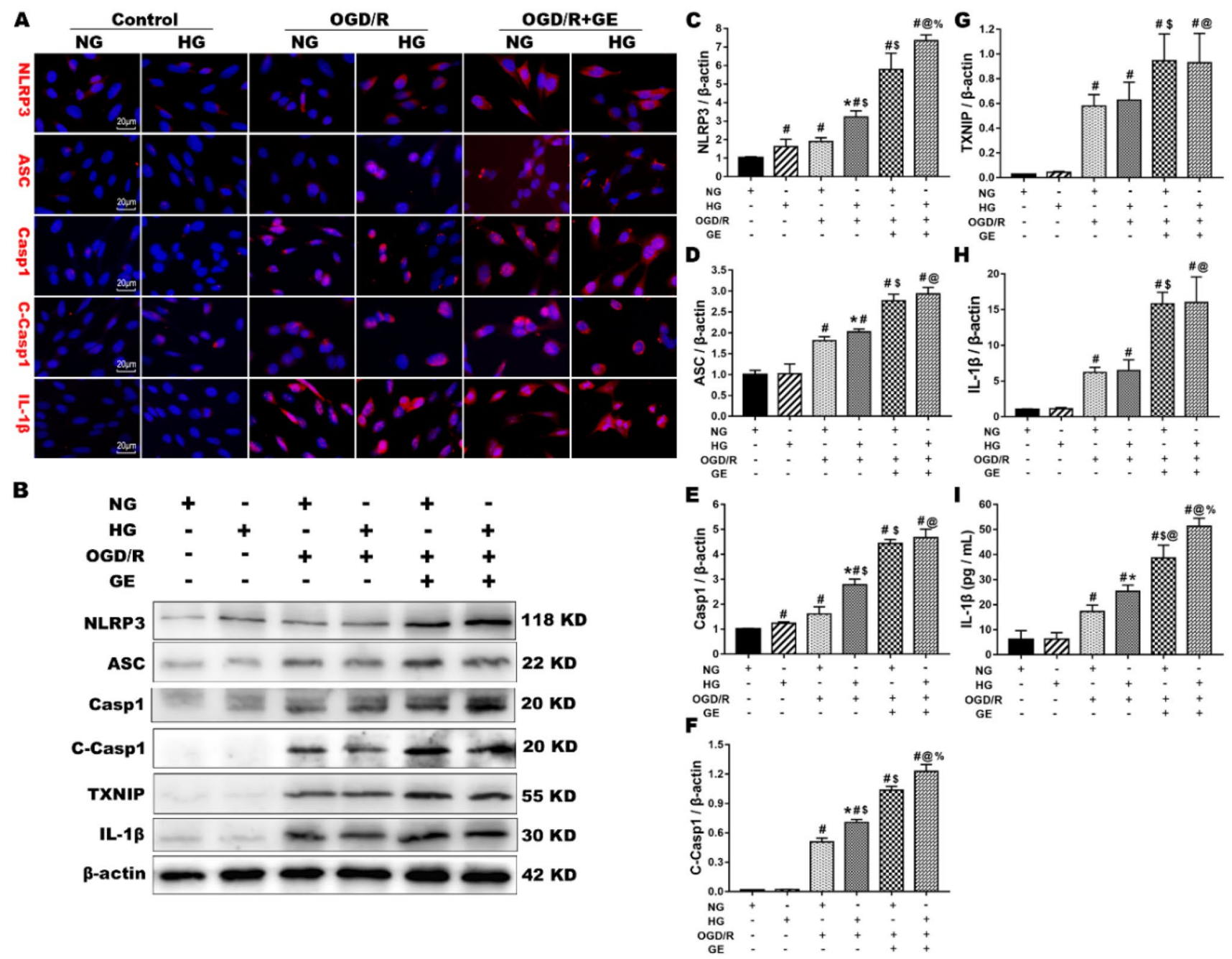

Fig. 5 UCP2 deficiency enhanced NLRP3 inflammasome activation in HT22 cells under OGD/R and high glucose conditions. a Double immunostaining of NLRP3, ASC, Caspase 1, Cleaved Caspase 1 , and IL-1 $\beta$ (red) with DAPI (blue)) was performed in the different groups. b Representative western blots showing NLRP3, ASC, Caspase 1, Cleaved Caspase 1, TXNIP, and IL-1 $\beta$ in the different groups.

increases in IL-1 $1 \beta$, and genipin treatment further increased the level of IL- $1 \beta$ in HT22 cell culture medium under normal and high glucose conditions. These results indicated that UCP2 deficiency enhanced NLRP3 inflammasome activation in HT22 cells under OGD/R and high glucose conditions.

\section{UCP2 Deficiency Enhanced the Production of ROS in HT22 Cells under OGD/R and High Glucose Conditions}

Excess ROS production causes different forms of DNA damage, resulting in cell death. We measured ROS production using the DHE probe. As shown in Fig. 6a, b, and c, OGD/R and $\mathrm{HG}+\mathrm{OGD} / \mathrm{R}$ caused significant increases in ROS and

c-h Quantification of the average NLRP3, ASC, Caspase 1, Cleaved Caspase 1 , TXNIP, and IL-1 $\beta$ expression normalized to $\beta$-actin. i The level of IL-1 $\beta$ in HT22 cell culture medium. The experiments were repeated three times in triplicate for each condition. ${ }^{\#} p<0.05$ vs. Control; * $p<0.05$ vs. HG; ${ }^{\$} p<0.05$ vs. NG+OGD/R; ${ }^{\circledR} p<0.05$ vs. $\mathrm{HG}+\mathrm{OGD} / \mathrm{R} ;{ }^{\%} p<0.05$ vs. $\mathrm{NG}+\mathrm{OGD} / \mathrm{R}+\mathrm{GE}$

MDA production compared with those of the control group $(p<0.01)$. Simultaneous treatment with genipin resulted in obvious increases in OGD/R-induced ROS and MDA production under normal or high glucose conditions $(p<0.01)$. Manganese SOD (SOD2/MnSOD) is a mitochondria-resident enzyme that functions as the first line in mitochondrial antioxidant defense. We measured the protein levels of SOD2 in the different groups by immunofluorescence and western blotting. The immunofluorescence results showed abundant staining of SOD2-positive neurons among normal HT22 cells. OGD/R obviously reduced the number of SOD2-positive cells. Concurrent treatment with genipin further decreased the immunoreactivity of SOD2 in ODG/R-exposed neurons. Western blot analysis demonstrated that the level of SOD2 protein was lower in the OGD/R group than in the control group, and 
A

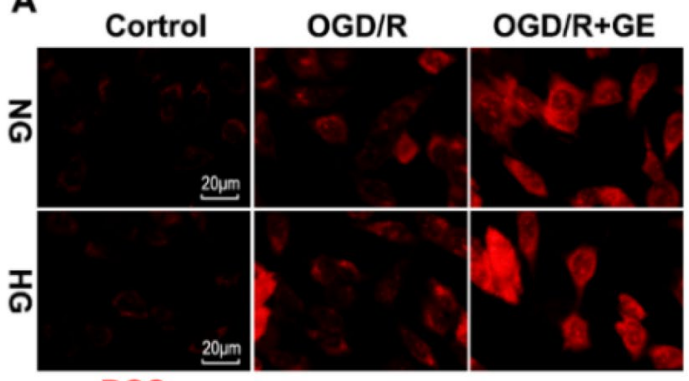

ROS

B

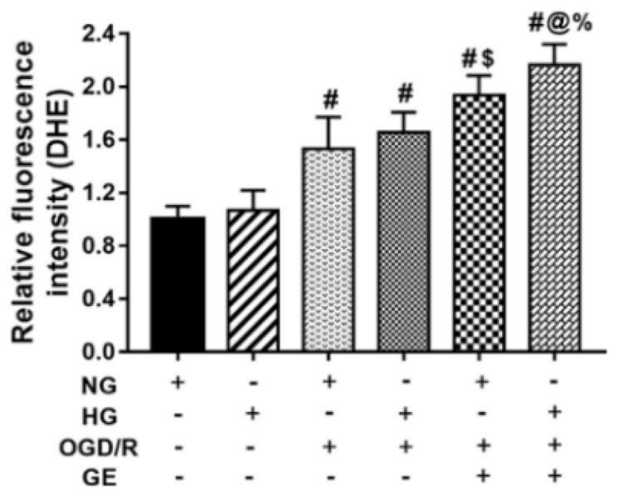

C

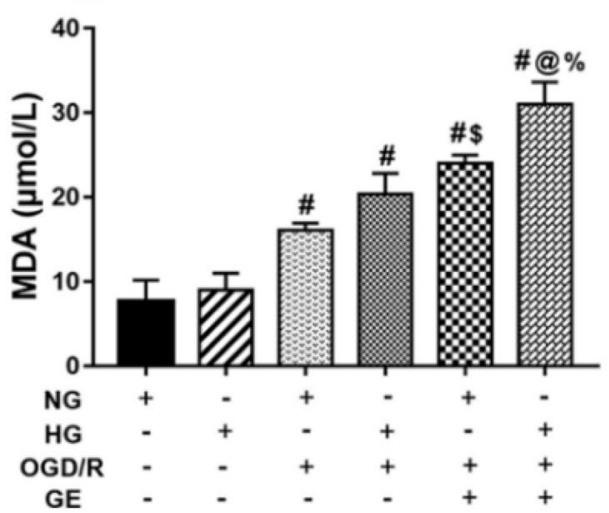

Fig. 6 UCP2 deficiency enhanced the production of ROS in HT22 cells under OGD/R and high glucose conditions. a DHE fluorescence. ROS were detected by the DHE probe (Red). b The presence of ROS was determined using DHE. $\mathbf{c}$ The MDA level in the different groups of HT22 cells. d SOD2 fluorescence. SOD (green color) was detected using antibodies. DAPI (blue color) labeled the nuclei. e Representa-

genipin further decreased the expression of SOD2 compared with that in the OGD/R group under normal or high glucose conditions. These results suggested that UCP2 deficiency enhanced ROS production in HT22 cells under OGD/R and high glucose conditions.

\section{Discussion}

Our study showed that UCP2 deficiency significantly increased histopathological changes and apoptosis after cerebral I/R in normoglycemic and hyperglycemic mice.

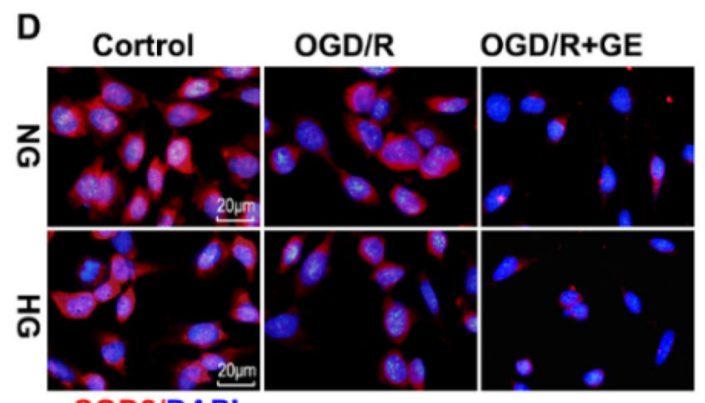

SOD2/DAPI

E

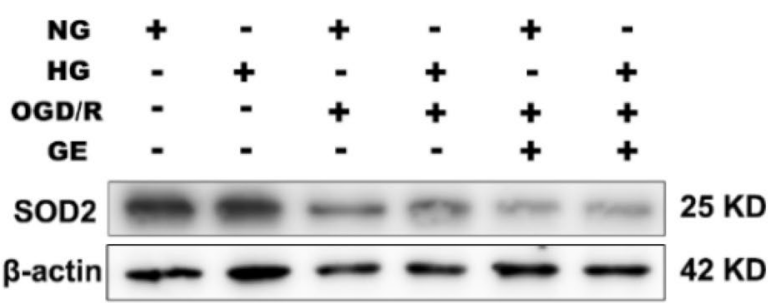

$\mathbf{F}$

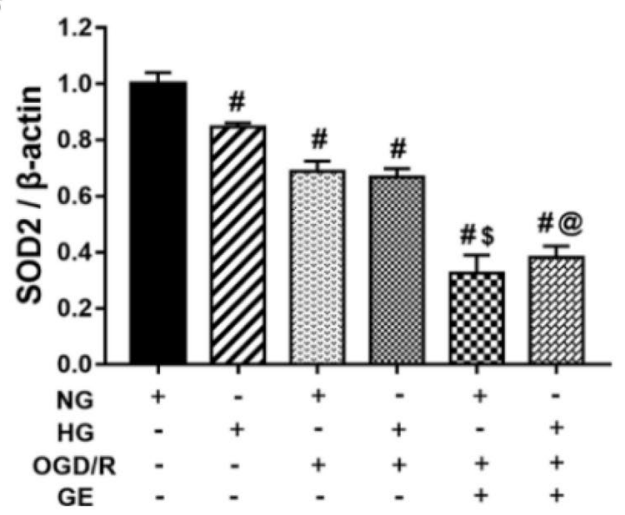

tive western blots showing SOD2 expression. $\mathbf{f}$ Quantification of the average SOD2 expression normalized to $\beta$-actin. The experiments were repeated three times in triplicate for each condition. ${ }^{*} p<0.05$ vs. Control; $* p<0.05$ vs. HG; ${ }^{\$} p<0.05$ vs. NG $+\mathrm{OGD} / \mathrm{R} ;{ }^{\circledR} p<0.05$ vs. $\mathrm{HG}+\mathrm{OGD} / \mathrm{R} ; \% p<0.05$ vs. $\mathrm{NG}+\mathrm{OGD} / \mathrm{R}+\mathrm{GE}$

Furthermore, UCP2 deficiency enhanced NLRP3 inflammasome activation in neurons in the context of hyperglycemia-exacerbated cerebral I/R damage. Moreover, UCP2 deficiency enhanced NLRP3 inflammasome activation and ROS production in HT22 cells under OGD/R and high glucose conditions. These findings suggest that UCP2 deficiency enhances NLRP3 inflammasome activation and ROS production in neurons in the context of hyperglycemia-exacerbated cerebral $\mathrm{I} / \mathrm{R}$ damage in vivo and in vitro.

UCP2 plays important roles in the process of cerebral I/R damage. The main function of UCP2 may be to stabilize the inner mitochondrial membrane potential and 
reduce ROS generation [5]. Previous studies indicated that UCP2 deficiency exacerbates infarct volume and mitochondrial dysfunction in normoglycemic and hyperglycemic animals subjected to cerebral I/R damage [11]. UCP2 deficiency upregulates inflammatory cytokines and suppresses antioxidants, and UCP2 overexpression inhibits proinflammatory cytokine expression and activates cell survival factors $[12,13]$. The neuroprotective effects of UCP2 are likely related to the regulation of ROS and neuroinflammation. Our data demonstrated that UCP2 deficiency significantly increased brain damage and apoptosis after I/R. The above results demonstrated that UCP2 plays important roles in neuroinflammation after cerebral I/R damage.

Recently, the NLRP3 inflammasome has been shown to serve as a critical contributor to cerebral I/R damage [14]. Previous studies have reported that the NLRP3 inflammasome is involved in neuronal cell death in ischemic stroke [15]. As has been reported, NLRP3 oligomerizes and recruits ASC. ASC can activate pro-Caspase 1 and induce cleavage into its active fragments. Then, cleaved Caspase 1 induces the formation of mature pro-inflammatory cytokines IL-1 $\beta$ and IL-18 $[16,17]$. The inflammatory cytokines IL-1 $\beta$ and IL-18 can cause cellular damage through autophagy and pyroptosis in cerebral I/R damage [18]. The present study indicated that the NLRP3 inflammasome was activated after cerebral I/R in both normoglycemic and hyperglycemic mice. Furthermore, UCP2 deficiency promoted NLRP3 inflammasome activation under hyperglycemia-exacerbated cerebral I/R damage. It has been observed that the levels of the NLRP3 inflammasome proteins IL- $1 \beta$ and IL-18 are upregulated in HT22 cells under OGD/R conditions [19]. However, some studies have shown that NLRP3 is expressed in astrocytes, endothelial cells and microglia but not neurons [14, 20, 21]. Moreover, some reports have shown that the NLRP3 inflammasome is activated in microglia but is not detected in astrocytes [22]. Therefore, it is not yet clear whether NLRP3 inflammasomes are specifically expressed and distributed in the brain after I/R. In this study, the immunofluorescence results showed that NLRP3 inflammasome activation occurred in neurons after I/R. These differences may be due to the different ischemia models, the duration of the ischemic insult, and the different interventions. Therefore, this study focused on the effect of UCP2 deficiency on the expression of inflammasomes in neurons in the context of hyperglycemia-exacerbated I/R damage. Similarly, the expression of NLRP3 and IL- $1 \beta$ increased in HT22 cells treated with high glucose and OGD/R relative to those of the control group. Furthermore, UCP2 deficiency enhanced NLRP3 inflammasome activation after hyperglycemia-exacerbated cerebral I/R damage in vivo and in vitro. However, the molecular and cellular mechanisms of NLRP3 activation remain unclear.
Some studies suggest that ROS are critical stimuli that activate the NLRP3 inflammasome [23, 24]. Experimental evidence demonstrates that an increase in ROS concentration following cellular stress leads to TXNIP-mediated recruitment of NLRP3 and subsequent NLRP3 activation [25]. It has been demonstrated that reducing ROS or NLRP3 or inhibiting Caspase- 1 abolishes ROS production and the upregulation of IL- $1 \beta$ and IL- 18 induced by ATP or LPS [26]. A previous study showed that soluble uric acid induced NLRP3 inflammasome activation by ROS production [27]. Moreover, tPA may stimulate NLRP3 inflammasome activation by generating increased ROS after hyperglycemia-exacerbated I/R damage [28]. In addition, overproduction of IL- $1 \beta$ could promote ROS production, resulting in oxidative damage after ischemia [23, $25,29]$. Overall, these findings indicate the importance of ROS-mediated promotion of NLRP3 inflammasome activation after cerebral I/R damage. However, many aspects of ROS-dependent NLRP3 inflammasome activation remain unknown. In this study, we found that UCP2 deficiency exacerbated NLRP3 inflammasome activation and increased ROS production in neurons after hyperglycemia-exacerbated cerebral $\mathrm{I} / \mathrm{R}$ damage in vivo and in vitro. Increasing evidence suggests that UCP2 may regulate mitochondrial potential and ROS production in cerebral $\mathrm{I} / \mathrm{R}$ damage $[30,31]$. The vast majority of published studies have reported that overexpression of UCP2 plays vital protective roles in cerebral I/R damage [31, 32]. Studies have confirmed that the upregulation of UCP2 can reduce ROS production in cerebral I/R damage [33]. Our previous study showed that UCP2 deficiency increased ROS production after cerebral I/R damage [34]. Taken together, the present study suggests that UCP2 deficiency enhances NLRP3 inflammasome activation by increasing ROS production in the context of hyperglycemia-exacerbated I/R damage. Hence, UCP2 is likely an upstream mediator of ROS generation and NLRP3 inflammasome activation after hyperglycemia-exacerbated I/R damage. Nevertheless, the inability to knock out UCP2 or express it at high levels in vitro is a limitation of the current study.

In summary, our data suggest that UCP2 deficiency enhances NLRP3 inflammasome activation and ROS production after neurons in hyperglycemia-exacerbated cerebral I/R damage in vivo and in vitro. UCP2 is likely an upstream mediator of ROS generation and NLRP3 inflammasome activation in hyperglycemia-exacerbated I/R damage. Although the underlying pathological mechanisms behind hyperglycemia-exacerbated I/R damage have not been fully investigated, our study provides a possible novel strategy for the treatment of stroke.

Acknowledgements We thank P. Andy Li of North Carolina Central University for effective research support activities. 
Author Contributions LJ and JZZ conceived and supervised the study; JZZ, LJ and TZ designed experiments; TZ and MTH performed experiments; TZ and XPZ analyzed data; TZ and MTH wrote the manuscript; LJ and JZZ made manuscript revisions. All authors have read and agreed to the published version of the manuscript.

Funding This study was supported by the National Science Foundation of China (31760280 to JZZ, 31960177 to LJ) and First-Class Discipline Construction Founded Project of NingXia Medical University and the School of Clinical Medicine (NXYLXK2017A05 to MTH). The funders had no role in the study design, data collection and analysis, decision to publish, or preparation of the manuscript.

\section{Compliance with Ethical Standards}

Conflict of interest The authors declare that they have no conflicts of interest.

Ethical Approval The present study was approved by the ethical review committee of Ningxia Medical University.

Open Access This article is licensed under a Creative Commons Attribution 4.0 International License, which permits use, sharing, adaptation, distribution and reproduction in any medium or format, as long as you give appropriate credit to the original author(s) and the source, provide a link to the Creative Commons licence, and indicate if changes were made. The images or other third party material in this article are included in the article's Creative Commons licence, unless indicated otherwise in a credit line to the material. If material is not included in the article's Creative Commons licence and your intended use is not permitted by statutory regulation or exceeds the permitted use, you will need to obtain permission directly from the copyright holder. To view a copy of this licence, visit http://creativecommons.org/licenses/by/4.0/.

\section{References}

1. Tziomalos K, Dimitriou P, Bouziana SD, Spanou M, Kostaki S, Angelopoulou SM, Papadopoulou M, Giampatzis V, Savopoulos C, Hatzitolios AI (2017) Stress hyperglycemia and acute ischemic stroke in-hospital outcome. Metabolism 67:99-105. https://doi. org/10.1016/j.metabol.2016.11.011

2. Zhu B, Pan Y, Jing J, Meng X, Zhao XQ, Liu LL, Wang YL, Wang YJ, Wang ZM (2019) Stress hyperglycemia and outcome of nondiabetic patients after acute ischemic stroke. Front Neurol 10:1003. https://doi.org/10.3389/fneur.2019.01003

3. Zhao J, Piao X, Wu Y, Liang SS, Han F, Liang Q, Shao SJ, Zhao DW (2020) Cepharanthine attenuates cerebral ischemia and reperfusion injury by reducing NLRP3 inflammasome-induced inflammation and oxidative stress via inhibiting 12/15-LOX signaling. Biomed Pharmacother 127:110151. https://doi.org/10.1016/j. biopha.2020.110151

4. Wu L, Xiong X, Wu X, Ye Y, Jian Z, Zhi Z, Gu L (2020) Targeting oxidative stress and inflammation to prevent ischemia-reperfusion injury. Front Mol Neurosci 13:28. https://doi.org/10.3389/fnmol. 2020.00028

5. Brand MD, Esteves TC (2005) Physiological functions of the mitochondrial uncoupling proteins UCP2 and UCP3. Cell Metab 2:85-93. https://doi.org/10.1016/j.cmet.2005.06.002

6. Haines BA, Mehta SL, Pratt SM, Warden CH, Li PA (2010) Deletion of mitochondrial uncoupling protein-2 increases ischemic brain damage after transient focal ischemia by altering gene expression patterns and enhancing inflammatory cytokines. $\mathbf{J}$ Cereb Blood Flow Metab 30:1825-1833. https://doi.org/10.1038/ jcbfm. 2010.52

7. Alfonso-Loeches S, Ureña-Peralta JR, Morillo-Bargues MJ, Cruz JOL, Guerri C (2014) Role of mitochondria ROS generation in ethanol-induced NLRP3 inflammasome activation and cell death in astroglial cells. Front Cell Neurosci 8:216. https://doi.org/10. 3389/fncel.2014.00216

8. Liu HD, Li W, Chen ZR, Hu YC, Zhang DD, Shen W, Zhou ML, Zhu L, Hang CH (2013) Expression of the NLRP3 inflammasome in cerebral cortex after traumatic brain injury in a rat model. Neurochem Res 38:2072-2083. https://doi.org/10.1007/ s11064-013-1115-z

9. Li PA, Shamloo M, Katsura KI, Smith ML, Siesjö BK (1995) Critical values for plasma glucose in aggravating ischaemic brain damage: correlation to extracellular pH. Neurobiol Dis 2:97-108. https://doi.org/10.1006/nbdi.1995.0010

10. Longa ZE, Weinstein PR, Carlson S, Cummins R (1989) Reversible middle cerebral artery occlusion without craniectomy in rats. Stroke 20:84-91. https://doi.org/10.1161/01.STR.20.1.84

11. He MT, Ma YM, Wang R, Zhang JZ, Jing L, Li PA (2020) Deletion of mitochondrial uncoupling protein 2 exacerbates mitochondrial damage in mice subjected to cerebral ischemia and reperfusion injury under both normo-and hyperglycemic conditions. Int J Biol Sci 16:2788-2802. https://doi.org/10.7150/ijbs.48204

12. Bai YS, Onuma H, Bai X, Medvedev AV, Misukonis M, Weinberg JB, Cao W, Robidoux J, Floering LM, Daniel KW, Collins S (2005) Persistent nuclear factor-kappa B activation in Ucp2 $2^{-/-}$mice leads to enhanced nitric oxide and inflammatory cytokine production. J Biol Chem 19:19062-19069. https://doi.org/10.1074/jbc. M500566200

13. Haines B, Li PA (2012) Overexpression of mitochondrial uncoupling protein 2 inhibits inflammatory cytokines and activates cell survival factors after cerebral ischemia. PLoS ONE 7:e31739. https://doi.org/10.1371/journal.pone.0031739

14. Guo Z, Yu S, Chen X, Zhu YR (2016) NLRP3 is involved in ischemia and reperfusion injury. CNS Neurol Disord Drug Targets 15:699-712. https://doi.org/10.2174/18715273156661603211 11829

15. Fann DYW, Lee SY, Manzanero S, Gelderlom PC, Bernreuther MG, Cheng YL, Thundyi J, Widiapradja KL, Foo SL, Wang YC, Li YI, Drummond GR, Basta M, Magnus T, Jo DG, Mattson MP, Sobey CG, Arumugam TV (2013) Intravenous immunoglobulin suppresses NLRP1 and NLRP3 inflammasome-mediated neuronal death in ischemic stroke. Cell Death Dis 4:e790-e790. https://doi. org/10.1038/cddis.2013.326

16. Gong Z, Pan J, Shen Q, Li M, Peng Y (2018) Mitochondrial dysfunction induces NLRP3 inflammasome activation during cerebral ischemia/reperfusion injury. J Neuroinflammation 15:242. https:// doi.org/10.1186/s12974-018-1282-6

17. Li Y, Wang R, Xue L, Yang Y, Zhi F (2020) Astilbin protects against cerebral ischaemia/reperfusion injury by inhibiting cellular apoptosis and ROS-NLRP3 inflammasome axis activation. Int Immunopharmacol. https://doi.org/10.1016/j.intimp.2020.106571

18. Zhou Y, Gu Y, Liu J (2019) BRD4 suppression alleviates cerebral ischemia-induced brain injury by blocking glial activation via the inhibition of inflammatory response and pyroptosis. Biochem Biophys Res Commun 519:481-488. https://doi.org/10.1016/j.bbrc. 2019.07.097

19. Wang CP, Zhang LZ, Li GC, Shi YW, Li JL, Zhang XC, Wang ZW, Ding F, Liang XM (2014) Mulberroside a protects against ischemic impairment in primary culture of rat cortical neurons after oxygen-glucose deprivation followed by reperfusion. J Neurosci Res 92:944-954. https://doi.org/10.1002/jnr.23374

20. Yang F, Wang Z, Wei X, Han H, Meng X, Zhang Y, Shi W, Li F, Xin T, Pang Q, Yi F (2014) NLRP3 deficiency ameliorates 
neurovascular damage in experimental ischemic stroke. J Cereb Blood Flow Metab 34:660-667. https://doi.org/10.1038/jcbfm. 2013.242

21. Freeman L, Guo H, David CN, Brichey J, Jha S, Ting JPY (2017) NLR members NLRC4 and NLRP3 mediate sterile inflammasome activation in microglia and astrocytes. J Exp Med 214:1351-1370. https://doi.org/10.1084/jem.20150237

22. Gustin A, Kirchmeyer M, Koncina E, Felten P, Losciuto S, Heurtaux T, Tardivel A, Heuschling P, Dostert C (2015) NLRP3 inflammasome is expressed and functional in mouse brain microglia but not in astrocytes. PLoS ONE 10:e130624. https://doi. org/10.1371/journal.pone.0130624

23. Tschopp J, Schroder K (2010) NLRP3 inflammasome activation: the convergence of multiple signalling pathways on ROS production? Nat Rev Immunol 10:210-215. https://doi.org/10.1038/nri27 25

24. Kelley N, Jeltema D, Duan Y, He Y (2019) The NLRP3 inflammasome: an overview of mechanisms of activation and regulation. Int J Mol Sci 20:3328. https://doi.org/10.3390/ijms20133328

25. Abais JM, Xia M, Zhang Y, Boini KM, Li PL (2015) Redox regulation of NLRP3 inflammasomes: ROS as trigger or effector? Antioxid Redox Signal 22:1111-1129. https://doi.org/10.1089/ ars.2014.5994

26. Alfonso-Loeches S, Urena-Peralta J, Morillo-Bargues MJ, Go'mez-Pinedo U, Guerri C (2016) Ethanol-induced TLR4/ NLRP3 neuroinflammatory response in microglial cells promotes leukocyte infiltration across the BBB. Neurochem Res 41:193209. https://doi.org/10.3389/fncel.2014.00216

27. Braga TT, Forni MF, Correa-Costa M, Ramos RN, Barbuto A, Brancon P, Castoldi A, Hiyane MI, Davanso MR, Latz E, Frankin BS, Kowaltowski AJ (2017) Camara NOS soluble uric acid activates the NLRP3 inflammasome. Sci Rep 7:1-14. https://doi.org/ 10.1038/srep39884

28. Ismael S, Nasoohi S, Yoo A, Ahmed HA, Ishrat T (2020) Tissue plasminogen activator promotes TXNIP-NLRP3 inflammasome activation after hyperglycemic stroke in mice. Mol Neurobiol. https://doi.org/10.1007/s12035-020-01893-7

29. Mathy-Hartert M, Hogge L, Sanchez C, Deby-Dupont G, Crielaard JM, Henrotin Y (2008) Interleukin-1 $\beta$ and interleukin-6 disturb the antioxidant enzyme system in bovine chondrocytes: a possible explanation for oxidative stress generation. Osteoarthritis Cartilage 16:756-763. https://doi.org/10.1016/j.joca.2007.10.009

30. Su J, Liu J, Yan XY, Zhang Y, Zhang JJ, Zhang LC, Sun LK (2017) Cytoprotective effect of the UCP2-SIRT3 signaling pathway by decreasing mitochondrial oxidative stress on cerebral ischemia-reperfusion injury. Int J Mol Sci 18:1599. https://doi. org/10.3390/ijms18071599

31. Mehta SL, Li PA (2009) Neuroprotective role of mitochondrial uncoupling protein 2 in cerebral stroke. J Cereb Blood Flow Metab 29:1069-1078. https://doi.org/10.1038/jcbfm.2009.4

32. Zhao B, Sun L, Jiang X, Zhang Y, Kang J, Meng H, Li H, Su $\mathrm{J}$ (2019) Genipin protects against cerebral ischemia-reperfusion injury by regulating the UCP2-SIRT3 signaling pathway. Eur J Pharmacol 845:56-64. https://doi.org/10.1016/j.ejphar.2018.12. 028

33. Olsson TD, Wieloch T, Diano S, Warden CH, Horvath TL, Mattiasson G (2008) Overexpression of UCP2 protects thalamic neurons following global ischemia in the mouse. J Cereb Blood Flow Metab 28:1186-1195. https://doi.org/10.1038/jcbfm.2008.8

34. He MT, Zhang T, Fan YC, Ma YM, Zhang JZ, Jing L, Li PA (2020) Deletion of mitochondrial uncoupling protein 2 exacerbates mitophagy and cell apoptosis after cerebral ischemia and reperfusion injury in mice. Int J Med Sci 17:2869-2878. https:// doi.org/10.7150/ijms.49849

Publisher's Note Springer Nature remains neutral with regard to jurisdictional claims in published maps and institutional affiliations. 